\title{
CuI-Catalyzed: One-Pot Synthesis of Diaryl Disulfides from Aryl Halides and Carbon Disulfide
}

\author{
Mohammad Soleiman-Beigi and Azadeh Izadi \\ Department of Chemistry, Ilam University, P.O. Box 69315-516, Ilam 6939177111, Iran \\ Correspondence should be addressed to Mohammad Soleiman-Beigi; soleimanbeigi@yahoo.com
}

Received 13 May 2013; Accepted 11 July 2013

Academic Editor: Albert Demonceau

Copyright ( 2013 M. Soleiman-Beigi and A. Izadi. This is an open access article distributed under the Creative Commons Attribution License, which permits unrestricted use, distribution, and reproduction in any medium, provided the original work is properly cited.

\begin{abstract}
A new application of carbon disulfide in the presence of $\mathrm{KF} / \mathrm{Al}_{2} \mathrm{O}_{3}$ is reported for the synthesis of organic symmetrical diaryl disulfides. These products were synthesized by one-pot reaction of aryl halides with the in situ generated trithiocarbonate ion in the presence of copper under air atmosphere.
\end{abstract}

\section{Introduction}

Carbon disulfide is a very important reagent for which many and varied uses have been reported in chemistry and also serves as an industrial and chemical nonpolar solvent [1-3]. The compound is frequently used as a building block in synthetic chemistry for the preparation of trithiocarbonates [49], dithio- and monothio-carbamates and carbonates $[10,11]$, thiourea $[12,13]$, and other organic compounds containing sulfur or thiocarbonyl $(\mathrm{C}=\mathrm{S})$ moiety [14-16]. Interestingly, carbon disulfide is also used for the synthesis of diaryl disulfides from diazonium salts under conditions of radicalic pathway $[17,18]$.

In continuation of our efforts to synthesize organic compounds containing sulfur and to use carbon disulfide in organic reactions $[4-6,19,20]$, we report a method for the direct synthesis of symmetrical diaryl disulfides via domino coupling reactions of aryl halides with the trithiocarbonate anion. However, recently symmetrical diaryl trithiocarbonates are synthesized from the reaction of $\mathrm{Na}_{2} \mathrm{~S}$ and $\mathrm{CS}_{2}$ with $\mathrm{Ar}-\mathrm{X}$ in the presence of $\mathrm{CuI}$ [21]. In our process, $\mathrm{KF} / \mathrm{Al}_{2} \mathrm{O}_{3}$ was used as a strong, recyclable, and heterogeneous base, which has a history of use in both synthetic methodology reactions [22-27] and the in situ production of the trithiocarbonate ion from carbon disulfide [4].

Organic disulfides are also valuable compounds in synthetic chemistry, industry, and biochemistry [28, 29]. They are typically prepared by oxidation of the corresponding thiols [30-36]. There are a limited number of methods for the direct synthesis of disulfides from aryl halides [20,37].

\section{Results and Discussion}

To find the optimal reaction conditions in terms of temperature and type of copper source, the coupling reaction of the carbon disulfide with iodobenzene was examined in the presence of $\mathrm{KF} / \mathrm{Al}_{2} \mathrm{O}_{3}$ under air (Scheme 1).

The trithiocarbonate anion was prepared by the in situ reaction of three equivalents of carbon disulfide in the presence of 1.0 gram of $\mathrm{KF}$ ( $40 \%$ by weight) $/ \mathrm{Al}_{2} \mathrm{O}_{3}$ in DMF. First, the effect of different copper salts was examined. As is shown in Table 1, copper iodide can catalyze the synthesis of diphenyl disulfide from phenyl iodide better than that from the other salts tested (Table 1, entry 4). As strong bases are commonly used for $\mathrm{CS}_{3}{ }^{2-}$ preparation $[10,11]$, $\mathrm{Cs}_{2} \mathrm{CO}_{3}$ and $\mathrm{KOH}$ were also tested to evaluate the efficiency of $\mathrm{KF} / \mathrm{Al}_{2} \mathrm{O}_{3}$. They catalyze the reaction under optimized reaction conditions, but not as well as $\mathrm{KF} / \mathrm{Al}_{2} \mathrm{O}_{3}$ as the reaction yields were $65 \%$ and $35 \%$, respectively.

It can be deduced from the previous literature reports that the temperature and the nature of an added ligand significantly affect the progress of coupling reactions of sulfur-containing compounds because some of them have not 


$$
\mathrm{Ph}-\mathrm{I}+\mathrm{CS}_{2} \underset{\text { (2) Cu source, } 5 \mathrm{~h}}{\stackrel{\text { (1) } \mathrm{KF} / \mathrm{Al}_{2} \mathrm{O}_{3}}{\text { r.t., } 15 \mathrm{~min}}} \mathrm{PhS}-\mathrm{SPh}
$$

SCHeme 1

TABLE 1: Optimization of the reaction temperature and screening of copper sources ${ }^{\mathrm{a}}$.

\begin{tabular}{lccc}
\hline Entry & Copper salt & Temp. $\left({ }^{\circ} \mathrm{C}\right)$ & Isolated yield (\%) \\
\hline 1 & $\mathrm{CuCl}$ & 110 & 65 \\
2 & $\mathrm{CuBr}$ & 110 & 72 \\
3 & $\mathrm{Cu}_{2} \mathrm{O}$ & 110 & 52 \\
4 & $\mathrm{CuI}$ & 110 & 95 \\
5 & $\mathrm{CuI}$ & 100 & 88 \\
6 & $\mathrm{CuI}$ & 80 & 83 \\
7 & $\mathrm{CuI}$ & 60 & 77 \\
8 & $\mathrm{CuI}$ & 25 & 15 \\
\hline
\end{tabular}

${ }^{\mathrm{a}}$ General reaction conditions: carbon disulfide $(6.0 \mathrm{mmol}), \mathrm{KF} / \mathrm{Al}_{2} \mathrm{O}_{3}$ (1.0 g, $40 \% \mathrm{KF}$ by weight), copper sources $(0.32 \mathrm{mmol})$, and iodobenzene $(2.0 \mathrm{mmol})$, in DMF $(4 \mathrm{~mL})$ for $5 \mathrm{~h}$.

been carried out at room temperature and/or in the absence of a ligand $[38,39]$. In our studies on the reaction, the best result was obtained at $110^{\circ} \mathrm{C}$. However, significant progress of the reaction was also observed at lower temperatures (Table 1 , entries 6 and 7). In addition, the reaction also proceeded well in the absence of a ligand. It seems that $\mathrm{CS}_{3}{ }^{2-}$ acts as both a ligand and a sulfur source.

It was expected that some symmetrical diaryl trithiocarbonate and thiol would be generated as by-products with the desired diaryl disulfide. However, no traces of these compounds were found at the end of the reaction. Thus, a large number of derivatives of symmetrical diaryl disulfides were synthesized in good to excellent yields under optimal conditions (Scheme 2, Table 2). Aryl bromides also reacted under these conditions, but not as well as aryl iodides.

A wide range of diaryl disulfides was synthesized according to the nature and position of the attachment of the substituents on the aryl groups. Thus, the products bearing different substituents, both electron-withdrawing and electron-donating, were obtained at the ortho-, para-, and metapositions.

Symmetrical diheteroaryl disulfides were readily synthesized from the corresponding heteroaryl halides (Table 2, entries 7 and 8). The optimal reaction conditions were also tested for the synthesis of symmetrical dialkyl disulfides (Table 2, entry 13) but were proved to be ineffective in yielding the dibenzyl disulfide and dibenzyl trithiocarbonate (as the major product); dibenzyl sulfide was obtained in $76 \%$ and $16 \%$ yields, respectively. Interestingly, a high chemoselectivity is observed in the coupling reactions (Table 2, entries 11 and $5)$. It is the case of 1-bromo-2,4-difluorobenzene to bis-(2,4diflouro phenyl) disulfide (Table 2, entry 11) and 1-bromo4-iodobenzene to bis-(4-bromo phenyl) disulfide (Table 2, entry 5) yielded as the main products. The reactivity of carbon-halide $(\mathrm{C}-\mathrm{X})$ bonds in aryl halides $(\mathrm{Ar}-\mathrm{X})$ probably

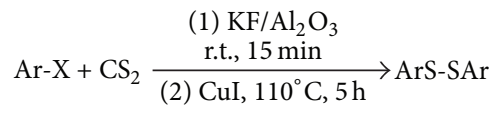

$\mathrm{X}=\mathrm{Br}, \mathrm{I}$

SCHEME 2

depends on the nature of the halides. As was seen, the reactivity of carbon-X bonds is in the order of $\mathrm{C}-\mathrm{I}>\mathrm{C}-\mathrm{Br}>$ C-F (Table 2, entries 4 and 10, 7 and 8, 5, 11).

Although we cannot yet clearly delineate the catalytic reaction pathway for the synthesis of diaryl disulfides from aryl halides and $\mathrm{CS}_{3}{ }^{2-}$, it is possible that this reaction proceeds through an addition/oxidation $\mathrm{Cu}(\mathrm{I})$-catalyst reaction of trithiocarbonate anion to aryl halides to generate an aryl trithiocarbonate ion via Ullman-type mechanism and then the fragmentation of formed aryl trithiocarbonate anion into carbon disulfide and aryl thiolate [40], which is followed by thiolate oxidation to corresponding disulfides in the presence of $\mathrm{KF} / \mathrm{Al}_{2} \mathrm{O}_{3}$ [41, 42]. Aryl (alkyl) halides are activated via a $\mathrm{Cu}(\mathrm{I}) / \mathrm{Cu}(\mathrm{II})$ redox couple single electron transfer (SET) [43].

\section{Conclusion}

In summary, in this study, carbon disulfide was used as an inexpensive and readily available source of sulfur in the presence of $\mathrm{KF} / \mathrm{Al}_{2} \mathrm{O}_{3}$. The reaction proceeds well under air. This strategy provides a new method for the direct synthesis of symmetrical diaryl disulfides from aryl halides and $\mathrm{CS}_{3}{ }^{2-}$. Other advantages of this process are the ability to reuse the recyclable base $\mathrm{KF} / \mathrm{Al}_{2} \mathrm{O}_{3}$, ease of performing and controlling the reaction as well as purification of the product, and the avoidance of expensive and/or dangerous reagents.

\section{Experimental}

4.1. Direct Synthesis of Diaryl Disulfides from Aryl Halides and Trithiocarbonate Ion: General Procedure. $6 \mathrm{mmol}$ of carbon disulfide and $2 \mathrm{mmol}$ of aryl halide were added to a two-neck flask containing $4 \mathrm{~mL}$ of DMF and 1.0 gram of $\mathrm{KF}$ ( $40 \%$ by weight) $/ \mathrm{Al}_{2} \mathrm{O}_{3}[4,44]$. The mixture was vigorously stirred for 15 minutes at room temperature on a hot-plate magnetic stirrer, so that it was blood red in color. Then $0.32 \mathrm{mmol}$ $(60 \mathrm{mg})$ of $\mathrm{CuI}$ was added, and the reaction continued at $110^{\circ} \mathrm{C}$ under air atmosphere and in a condenser until the reaction was completed $(5 \mathrm{~h})$. The reaction progress was controlled by TLC. The reaction mixture was then filtered, the filtrate was evaporated under vacuum, $\mathrm{CH}_{2} \mathrm{Cl}_{2}(20 \mathrm{~mL})$ was added, and the mixture washed with $\mathrm{H}_{2} \mathrm{O}(2 * 15 \mathrm{~mL})$. The organic layer was dried over anhydrous $\mathrm{Na}_{2} \mathrm{SO}_{4}$. The solvent was evaporated to give the crude diaryl disulfide, which was purified by plate chromatography (silica gel, $n$ hexane: ethyl acetate 20:1). All the products are known compounds and were characterized by comparison of NMR spectral data and melting points with those reported in the literature. 
TABLE 2: CuI-catalyzed and $\mathrm{KF} / \mathrm{Al}_{2} \mathrm{O}_{3}$ mediated, direct synthesis of diaryl disulfides from aryl halides and $\mathrm{CS}_{3}{ }^{2-}$ at $110^{\circ} \mathrm{C}$.

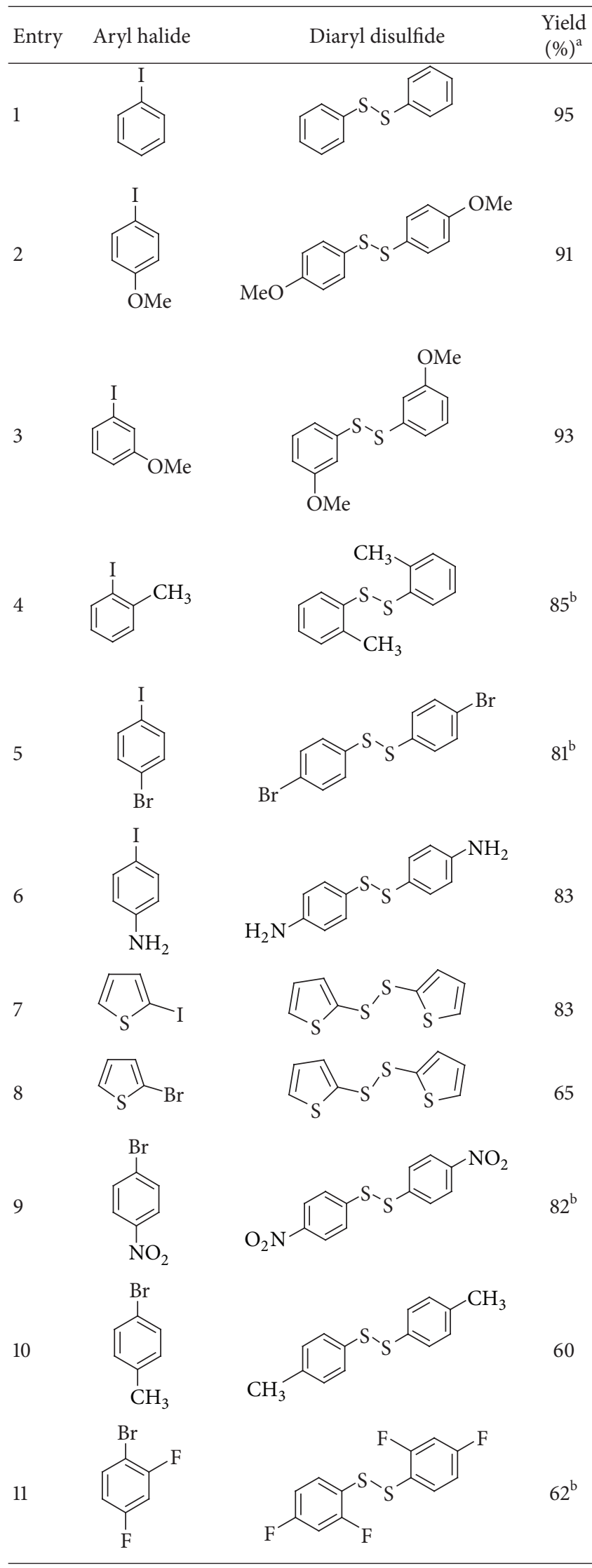

TABLE 2: Continued.

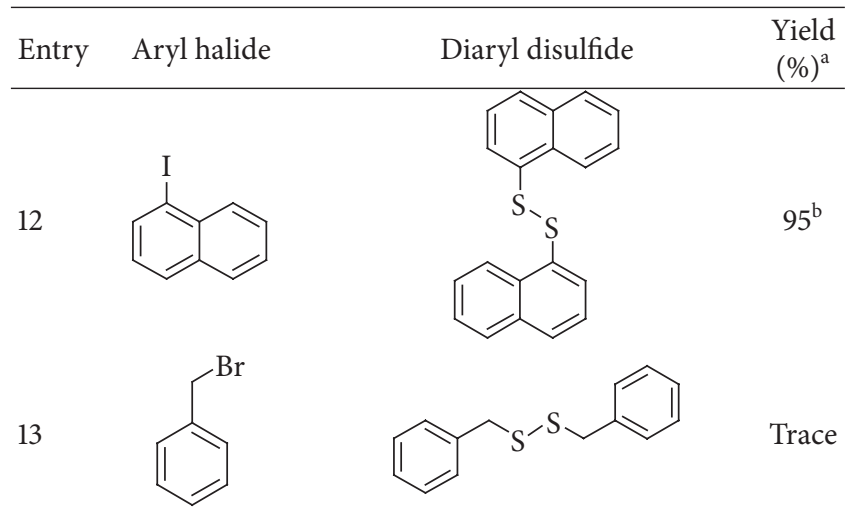

${ }^{a}$ Yield of the isolated product. ${ }^{b}$ A small amount of the corresponding diaryl sulfide derivative was formed as by-product $(5-10 \%)$.

4.2. Selected Spectral Data for Representative Disulfides. Diphenyl Disulfide (Table 2, entry 1). $\mathrm{mp}=59-60^{\circ} \mathrm{C}(59-$ $61^{\circ} \mathrm{C}$ lit. [31]). ${ }^{1} \mathrm{H}$ NMR $\left(\mathrm{CDCl}_{3}, 400 \mathrm{MHz}\right): \delta=7.24-7.36$ $(\mathrm{m}, 6 \mathrm{H}), 7.54(\mathrm{~m}, 4 \mathrm{H}) .{ }^{13} \mathrm{C} \mathrm{NMR}\left(\mathrm{CDCl}_{3}, 100 \mathrm{MHz}\right): \delta=$ 127.2, 127.5, 129.1, 137.0.

Bis(4-mathoxyphenyl) Disulfide (Table 2, entry 2). $\mathrm{mp}=42$ $43^{\circ} \mathrm{C}\left(42-43^{\circ} \mathrm{C}\right.$ lit. $\left.[34,35]\right) .{ }^{1} \mathrm{H}$ NMR $\left(\mathrm{CDCl}_{3}, 400 \mathrm{MHz}\right)$ : $\delta=3.82(\mathrm{~s}, 6 \mathrm{H}), 6.87(\mathrm{~d}, J=8.8 \mathrm{~Hz}, 4 \mathrm{H}), 7.32(\mathrm{~d}$, $J=8.8 \mathrm{~Hz}, 4 \mathrm{H}) \cdot{ }^{13} \mathrm{C} \mathrm{NMR}\left(\mathrm{CDCl}_{3}, 100 \mathrm{MHz}\right): \delta=$ $55.4,114.7,127.4,132.8,159.0$.

Bis(thiophen-2-yl) Disulfide (Table 2, entry 7). $\mathrm{mp}=54-55^{\circ} \mathrm{C}$ (54-56 ${ }^{\circ} \mathrm{C}$ lit. [36]). ${ }^{1} \mathrm{H}$ NMR $\left(\mathrm{CDCl}_{3}, 400 \mathrm{MHz}\right): \delta={ }^{1} \mathrm{H}$ $\operatorname{NMR}\left(\mathrm{CDCl}_{3}, 400 \mathrm{MHz}\right): \delta 6.97-7.00(\mathrm{~m}, 2 \mathrm{H}), 7.22-7.25(\mathrm{~m}$, $2 \mathrm{H}), 7.36-7.38(\mathrm{~m}, 2 \mathrm{H}) .{ }^{13} \mathrm{C}$ NMR $\left(\mathrm{CDCl}_{3}, 100 \mathrm{MHz}\right): \delta=$ $115.4,120.7,129.7,155.4$

\section{References}

[1] H. Werner, "Novel coordination compounds formed from cs2 and heteroallenes," Coordination Chemistry Reviews, vol. 43, pp. 165-185, 1982.

[2] J. E. Stauffer, "Extraction of bitumen from oil sands," US, 0101980, 2010.

[3] B. Ochiai and T. Endo, "Carbon dioxide and carbon disulfide as resources for functional polymers," Progress in Polymer Science, vol. 30, no. 2, pp. 183-215, 2005.

[4] B. Movassagh, M. Soleiman-Beigi, and M. Nazari, "A facile $\mathrm{KF} / \mathrm{Al}_{2} \mathrm{O}_{3}$-mediated, one-pot synthesis of symmetrical trithiocarbonates from alkyl halides and carbon disulfide," Chemistry Letters, vol. 37, no. 1, pp. 22-23, 2008.

[5] M. Soleiman-Beigi, Z. Arzehgar, and B. Movassagh, “TBAHcatalyzed one-pot synthesis of symmetrical trithiocarbonates from alkyl halides and carbon disulfide under neat aqueous conditions," Synthesis, no. 3, pp. 392-394, 2010.

[6] B. Movassagh and M. Soleiman-Beigi, "Triethylaminecatalyzed one-pot synthesis of trithiocarbonates from carbon disulfide, thiols, and alkyl halides in water," Monatshefte fur Chemie, vol. 139, no. 8, pp. 927-930, 2008. 
[7] N. Aoyagi, B. Ochiai, H. Mori, and T. Endo, "Mild and efficient one-step synthesis of trithiocarbonates using minimum amount of $\mathrm{CS}_{2}$," Synlett, no. 4, pp. 636-638, 2006.

[8] I. Degani, R. Fochi, A. Gatti, and V. Regondi, "Phase-transfer synthesis of symmetrical and unsymmetrical dialkyl trithiocarbonates," Synthesis, no. 11, pp. 894-899, 1986.

[9] B. Movassagh and S. J. Alapour, " $\mathrm{K}_{3} \mathrm{PO}_{4}$-mediated one-pot synthesis of symmetrical trithiocarbonates," Journal of Sulfur Chemistry, vol. 34, no. 3, pp. 222-226, 2013.

[10] R. N. Salvatore, S. Sahab, and K. W. Jung, "Mild and efficient synthesis of thiocarbonates and thiocarbamates via a threecomponent coupling utilizing $\mathrm{Cs}_{2} \mathrm{CO}_{3}$ and TBAI," Tetrahedron Letters, vol. 42, no. 11, pp. 2055-2058, 2001.

[11] F. Dehmel, S. Weinbrenner, H. Julius et al., "Trithiocarbonates as a novel class of HDAC inhibitors: SAR studies, isoenzyme selectivity, and pharmacolozgical profiles," Journal of Medicinal Chemistry, vol. 51, no. 13, pp. 3985-4001, 2008.

[12] R. Ballini, G. Bosica, D. Fiorini et al., "MCM-41-TBD as a new, efficient, supported heterogeneous catalyst for the synthesis of thioureas," Tetrahedron Letters, vol. 43, no. 47, pp. 8445-8447, 2002.

[13] U. Boas, H. Gertz, J. B. Christensen, and P. M. H. Heegaard, "Facile synthesis of aliphatic isothiocyanates and thioureas on solid phase using peptide coupling reagents," Tetrahedron Letters, vol. 45, no. 2, pp. 269-272, 2004.

[14] M. Ballabeni, R. Ballini, F. Bigi et al., "Synthesis of symmetrical $\mathrm{N}, \mathrm{N}^{\prime}$-disubstituted thioureas and heterocyclic thiones from amines and $\mathrm{CS} 2$ over a $\mathrm{ZnO} / \mathrm{Al}_{2} \mathrm{O}_{3}$ composite as heterogeneous and reusable catalyst," Journal of Organic Chemistry, vol. 64, no. 3, pp. 1029-1032, 1999.

[15] P. A. Ottersbach, P. W. Elsinghorst, H.-G. Hacker, and M. Gutschow, "Direct formation of ring-fused 1,3-thiazine-2,4dithiones from aromatic o-amino carboxylic acids: observation of a carbon disulfide mediated thionation," Organic Letters, vol. 12, no. 16, pp. 3662-3665, 2010.

[16] M. Benaglia, E. Rizzardo, A. Alberti, and M. Guerra, "Searching for more effective agents and conditions for the RAFT polymerization of MMA: influence of dithioester substituents, solvent, and temperature," Macromolecules, vol. 38, no. 8, pp. 3129-3140, 2005.

[17] F. Barba, F. Ranz, and B. Batanero, "Electrochemical transformation of diazonium salts into diaryl disulfides," Tetrahedron Letters, vol. 50, no. 49, pp. 6798-6799, 2009.

[18] L. Benati and P. C. Montevecchi, "Reactivity of carbon disulfide with aryl radicals," Journal of Organic Chemistry, vol. 41, no. 15, pp. 2639-2640, 1976.

[19] M. Soleiman-Beigi, R. Aryan, M. Yousofizadeh, and Sh. Khosravi, "A Combined Synthetic and DFT Study on the CatalystFree and Solvent-Assisted Synthesis of 1,3,4-Oxadiazole-2-Thiol Derivatives," Journal of Chemistry, Article ID 476358, pp. 1-6, 2013.

[20] M. Soleiman-Beigi and F. Mohammadi, "A novel coppercatalyzed, one-pot synthesis of symmetric organic disulfides from alkyl and aryl halides: potassium 5-methyl-1,3,4oxadiazole-2-thiolate as a novel sulfur transfer reagent," Tetrahedron Letters, vol. 53, no. 52, pp. 7028-7030, 2012.

[21] M. Gholinejad, "One-pot synthesis of symmetrical diaryl trithiocarbonates through copper-catalyzed coupling of aryl compounds, sodium sulfide, and carbon disulfide," European Journal of Organic Chemistry, no. 2, pp. 257-259, 2013.

[22] G. W. Kabalka, L. Wang, V. Namboodiri, and R. M. Pagni, "Rapid microwave-enhanced, solventless Sonogashira coupling reaction on alumina," Tetrahedron Letters, vol. 41, no. 27, pp. 5151-5154, 2000.

[23] B. E. Blass, "KF/ $/ \mathrm{Al}_{2} \mathrm{O}_{3}$ Mediated organic synthesis," Tetrahedron, vol. 58, no. 46, pp. 9301-9320, 2002.

[24] A. Zare, A. Hasaninejad, M. H. Beyzavi et al., " $\mathrm{KF} / \mathrm{Al}_{2} \mathrm{O}_{3}$ as a highly efficient, green, heterogeneous, and reusable catalytic system for the solvent-free synthesis of carboacyclic nucleosides via Michael addition reaction," Synthetic Communications, vol. 39, no. 1, pp. 139-157, 2009.

[25] A. Zare, A. Hasaninejad, M. H. Beyzavi et al., " $\mathrm{KF} / \mathrm{Al}_{2} \mathrm{O}_{3}$ as an efficient, green, and reusable catalytic system for the solvent-free synthesis of N-Alkyl derivatives of sulfonamides via michael reactions," Phosphorus, Sulfur and Silicon and the Related Elements, vol. 184, no. 7, pp. 1702-1712, 2009.

[26] A. Zare, A. Hasaninejad, A. R. Moosavi-Zare et al., " $\mathrm{KF} / \mathrm{Al}_{2} \mathrm{O}_{3}$ as a highly efficient reagent for the synthesis of $\mathrm{N}$-aryl derivatives of pyrimidine and purine nucleobases," Arkivoc, vol. 2008, no. 16, pp. 178-188, 2008.

[27] A. Zare, A. Hasaninejad, A. R. Moosavi-Zre et al., " $\mathrm{KF} / \mathrm{Al}_{2} \mathrm{O}_{3}$ as an efficient catalyst for the synthesis of $\mathrm{N}$-alkylphthalimides," Journal of the Chemical Society of Pakistan, vol. 31, no. 2, pp. 309313, 2009.

[28] S. Oae, Organic Sulfur Chemistry: Structure and Mechanism, CRC, Boca Raton, Fla, USA, 1991.

[29] R. J. Cremlyn, An Introduction to Organosulfur Chemistry, Wiley and Sons, New York, NY, USA, 1996.

[30] A. Christoforou, G. Nicolaou, and Y. Elemes, "NPhenyltriazolinedione as an efficient, selective, and reusable reagent for the oxidation of thiols to disulfides," Tetrahedron Letters, vol. 47, no. 52, pp. 9211-9213, 2006.

[31] R. Leino and J.-E. Lönnqvist, "A very simple method for the preparation of symmetrical disulfides," Tetrahedron Letters, vol. 45, no. 46, pp. 8489-8491, 2004.

[32] K. Tanaka and K. Ajiki, "Cationic rhodium(I)/PPh3 complexcatalyzed dehydrogenation of alkanethiols to disulfides under inert atmosphere," Tetrahedron Letters, vol. 45, no. 1, pp. 25-27, 2004.

[33] R. Hunter, M. Caira, and N. Stellenboom, "Inexpensive, one-pot synthesis of unsymmetrical disulfides using 1chlorobenzotriazole," Journal of Organic Chemistry, vol. 71, no. 21, pp. 8268-8271, 2006.

[34] J. K. Vandavasi, W.-P. Hu, C.-Y. Chen, and J.-J. Wang, "Efficient synthesis of unsymmetrical disulfides," Tetrahedron, vol. 67, no. 46, pp. 8895-8901, 2011.

[35] C. C. Silveira and S. R. Mendes, "Catalytic oxidation of thiols to disulfides using iodine and $\mathrm{CeCl}_{3}-7 \mathrm{H}_{2} \mathrm{O}$ in graphite," Tetrahedron Letters, vol. 48, no. 42, pp. 7469-7471, 2007.

[36] G. W. Kabalka, M. S. Reddy, and M.-L. Yao, "Synthesis of diaryl disulfides via the reductive coupling of arylsulfonyl chlorides," Tetrahedron Letters, vol. 50, no. 52, pp. 7340-7342, 2009.

[37] J. E. Arguello, L. C. Schmidt, and A. B. Penenory, "'One-Pot' two-step synthesis of aryl sulfur compounds by photoinduced reactions of thiourea anion with aryl halides," Organic Letters, vol. 5, no. 22, pp. 4133-4136, 2003.

[38] S. Yasuike, M. Nishioka, N. Kakusawa, and J. Kurita, "Simple and efficient copper-catalyzed S-arylation of diaryl disulfides with triarylbismuthanes under aerobic conditions," Tetrahedron Letters, vol. 52, no. 48, pp. 6403-6406, 2011.

[39] B. Basu, B. Mandal, S. Das, and S. Kundu, "Catechol violet as new, efficient, and versatile ligand for $\mathrm{Cu}(\mathrm{I})$-catalyzed $\mathrm{C}$ S coupling reactions," Tetrahedron Letters, vol. 50, no. 39, pp. 5523-5528, 2009. 
[40] E. J. Lenardão, R. G. Lara, M. S. Silva, R. G. Jacob, and G. Perin, "Clean and fast oxidative transformation of thiols to disulfides under solvent-free conditions," Tetrahedron Letters, vol. 48, no. 43, pp. 7668-7670, 2007.

[41] S. Tanimoto, T. Oida, H. Ikehira, and M. Okano, "Synthesis and Lithiation of 2-Alkylthio- and 2-Arylthio-1,3-dithiolanes," Bulletin of the Chemical Society of Japan, vol. 55, no. 6, pp. 19771978, 1982.

[42] A. Sugawara, M. Shirahata, S. Sato, and R. Sato, "One-pot synthesis of alkyl aryl trithiocarbonates from benzenethiols, alkyl halides, and carbon disulfide with a phase-transfer catalyst," Bulletin of the Chemical Society of Japan, vol. 57, no. 11, pp. 33533354, 1984.

[43] E. Sperotto, G. P. M. Van Klink, G. Van Koten, and J. G. De Vries, "The mechanism of the modified Ullmann reaction," Dalton Transactions, vol. 39, no. 43, pp. 10338-10351, 2010.

[44] V. K. Yadav, K. Ganesh Babu, and M. Mittal, " $\mathrm{KF}-\mathrm{Al}_{2} \mathrm{O}_{3}$ is an efficient solid support reagent for the acetylation of amines, alcohols, and phenols. Impeding effect of solvent on the reaction rate," Tetrahedron, vol. 57, no. 32, pp. 7047-7051, 2001. 

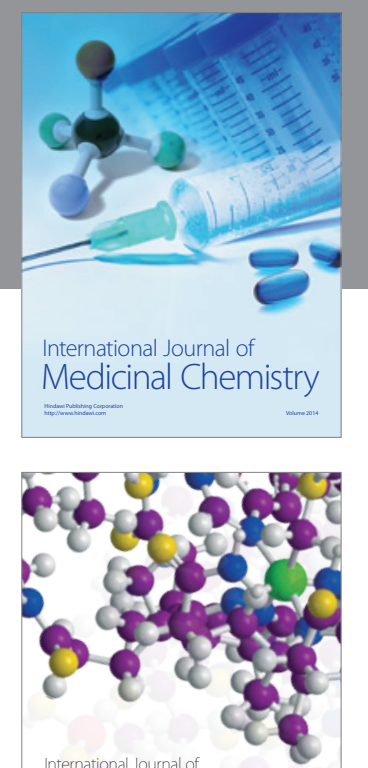

\section{Carbohydrate} Chemistry

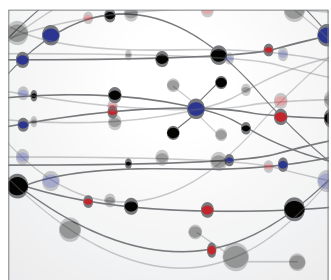

The Scientific World Journal
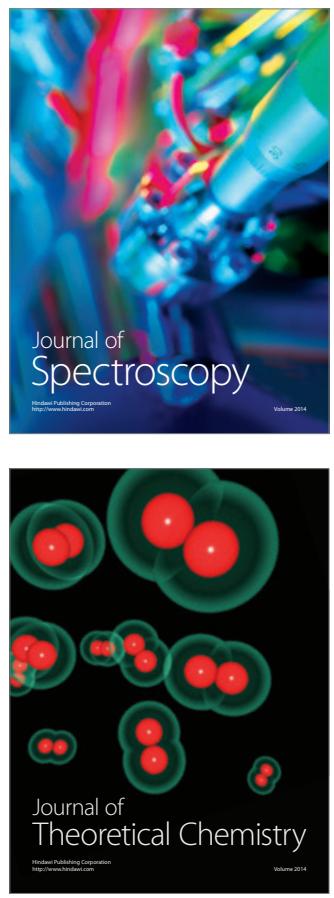
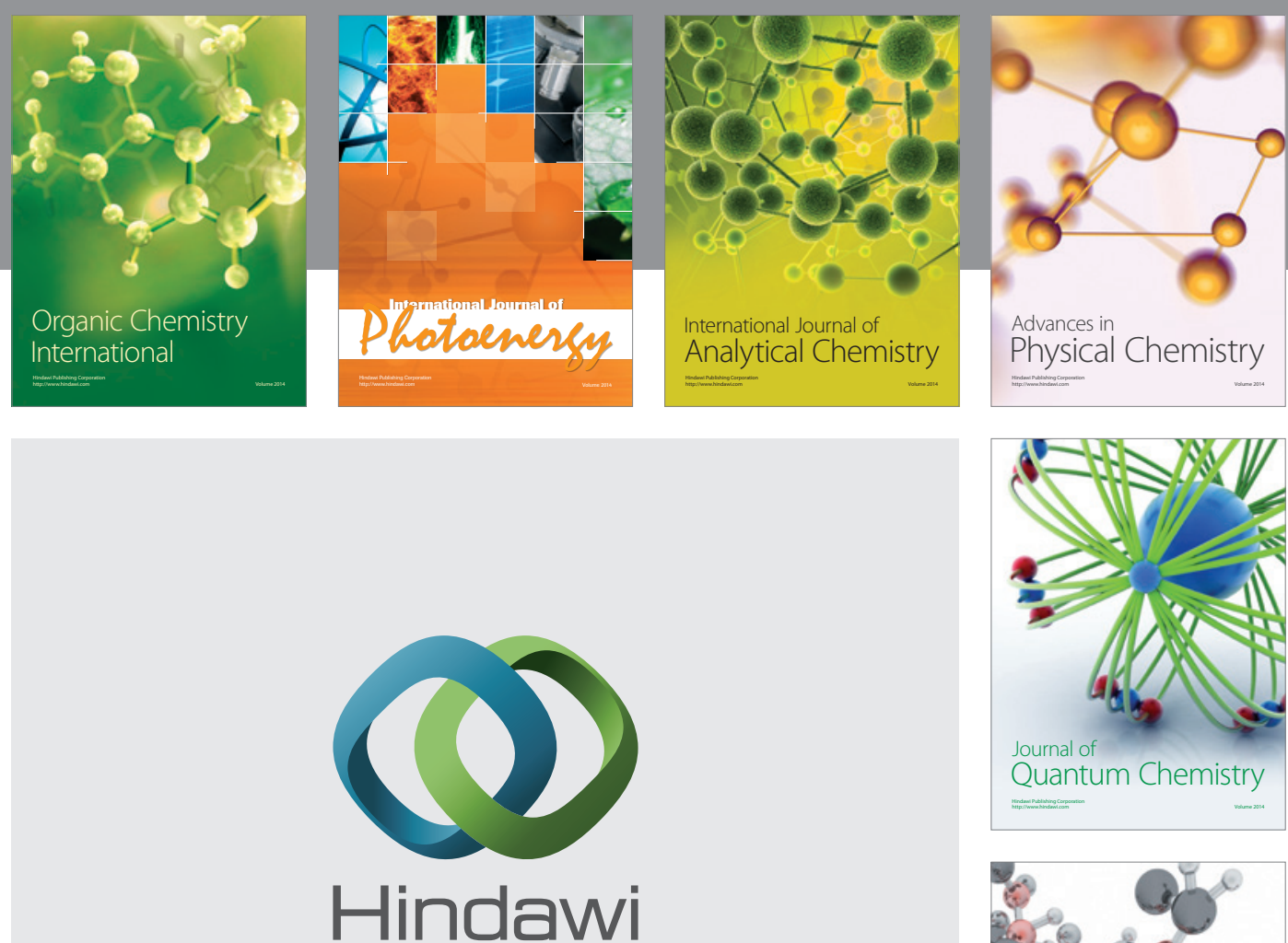

Submit your manuscripts at

http://www.hindawi.com

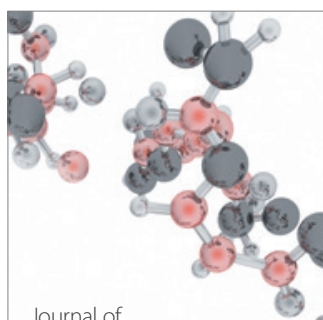

Analytical Methods

in Chemistry

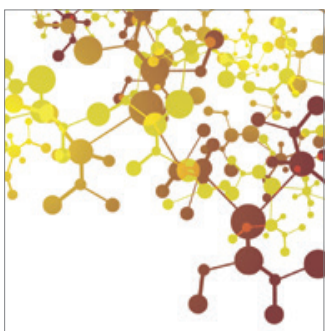

Journal of

Applied Chemistry

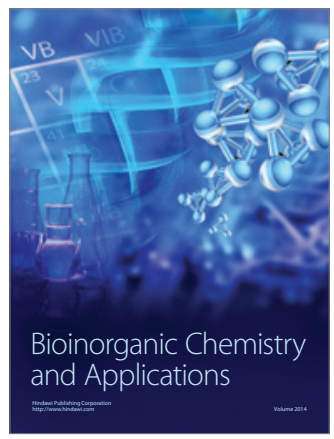

Inorganic Chemistry
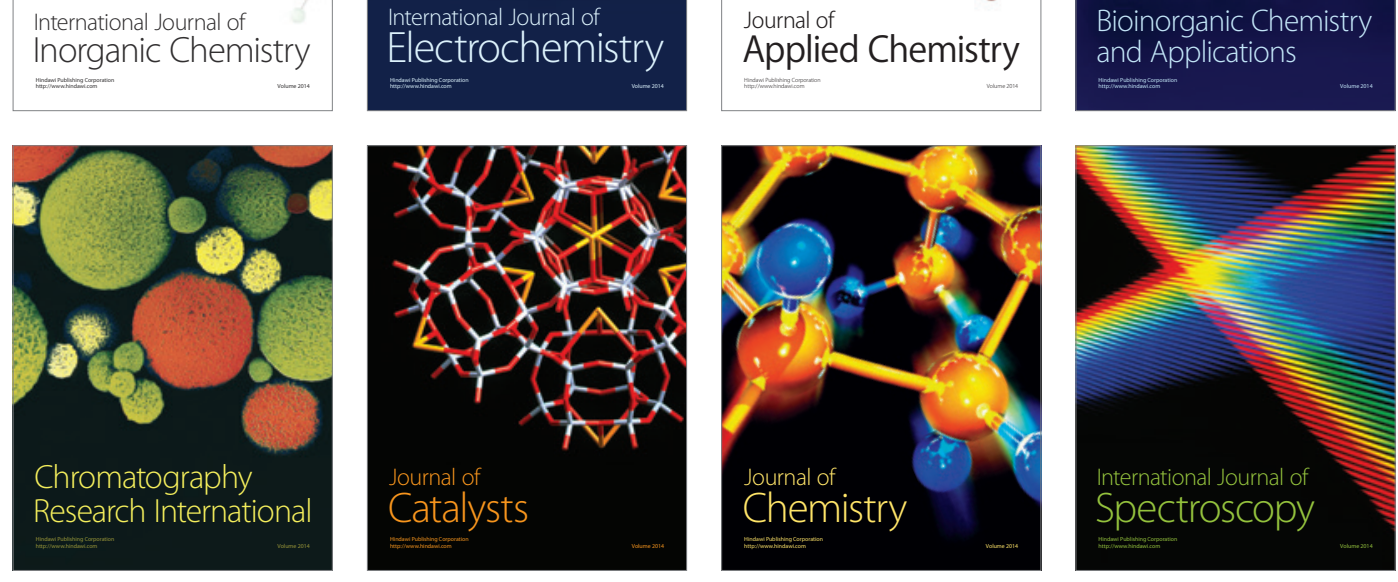